\title{
Increased expression of major histocompatibility complex (MHC) class I transplantation antigens in bovine trophoblast cells before fusion with maternal cells
}

\author{
D. R. J. Bainbridge ${ }^{1}$, I. L. Sargent ${ }^{2}$ and S. A. Ellis ${ }^{3}$ \\ ${ }^{1}$ Reproduction and Development Group, Royal Veterinary College, Potters Bar EN6 1NB, UK; \\ ${ }^{2}$ Nuffield Department of Obstetrics and Gynaecology, John Radcliffe Hospital, Oxford \\ OX3 9DU, UK; and Institute for Animal Health, Compton, Berkshire RG20 7NN, UK
}

The mammalian fetus is potentially at risk from maternal immune attack because it can express paternally inherited polymorphic antigens, including those encoded by the major histocompatibility complex (MHC). The aim of this study was to investigate in more detail MHC class I upregulation by binucleate trophoblast cells in the bovine placenta. A method was developed to isolate binucleate cells by enzymatic disaggregation and density gradient centrifugation of bovine placental cotyledons. In cytospin preparations, $25-30 \%$ of purified binucleate cells stained positively with antibodies that recognize bovine MHC class I. The same antibodies were used to immunoprecipitate radiolabelled class I molecules from lysates of binucleate cells and fetal peripheral blood mononuclear cells. The protein species isolated from the two types of cell were similar in size and degree of glycosylation. PCR amplification of cDNA generated from binucleate cells and subsequent sequence analysis demonstrated transcription of MHC class I mRNA species similar to those found in fetal peripheral blood mononuclear cells, and there was no evidence of genetic imprinting of paternally inherited alleles. These results indicate that binucleate cells upregulate expression of $\mathrm{MHC}$ class I as they differentiate from MHC-negative uninucleate trophoblast cells. This finding has important implications for the immunological status of the fetus, as binucleate trophoblast cells are destined to cross to the maternal side of the placenta where they fuse with maternal cells. The immunological function of the resulting antigenically mixed fetomaternal hybrid minisyncytia is unknown.

\section{Introduction}

The evolution of prolonged pregnancy in eutherian mammals has not been without potential risk. Approximately half of the genetic material of all mammalian fetuses is paternally inherited. In outbred populations, this means that the fetus is likely to express antigens to which the maternal immune system has not been exposed. As a result, the 'semi-foreign' or semiallogeneic fetus is potentially at risk of rejection by the maternal immune system, in the same manner in which a transplanted organ would be rejected. However, rejection of the fetus by the maternal immune system is not a common feature of pregnancy, presumably because methods have evolved in eutherian mammals to prevent such rejection occurring (Bainbridge, 2000)

As soon as the immunological predicament of the mammalian fetus was identified, possible strategies by which the fetus might avoid maternal immune attack were proposed (Medawar, 1953). These strategies included modulation of the maternal immune system to avoid recognition of the fetus, a placental barrier to maternal immune effector mechanisms and downregulation of

Email: dbainbridge@rvc.ac.uk immunologically 'provocative' molecules on fetal trophoblast cells. Although it appears that all of these strategies are used to different extents by different species, downregulation of immunologically 'provocative' molecules has received the most attention.

In particular, studies have focused on trophoblast expression of antigens encoded by the major histocompatibility complex (MHC). These antigens are responsible for most transplantation rejection reactions, and this exceptional ability to provoke rejection is thought to result from two important features of the MHC. First, in outbred populations, an extremely high degree of genetic polymorphism is maintained at many $\mathrm{MHC}$ loci and consequently tissues from a donor individual will almost always bear MHC antigens to which the immune system of a recipient individual has never been exposed. Second, a major physiological function of MHC proteins is to bind to a receptor on T-lymphocytes during the initiation of acquired immune responses, and thus MHC antigens on transplanted tissue are particularly effective at inducing such responses.

Considering the ability of these antigens to induce transplantation rejection, it is perhaps not unexpected that MHC class I molecules, which are present on almost all other types of cell in the body, are downregulated on many trophoblast populations in humans (Redman et al., 1984), 
horses (Donaldson et al., 1990), pigs (Ramsoondar et al., 1999), sheep (Gogolin-Ewens et al., 1989) and rats (Kanbour et al., 1987). Indeed, reduced expression of trophoblast $\mathrm{MHC}$ class I is thought to be an important strategy for ensuring fetal survival in most mammals.

In cattle, MHC class I downregulation is thought to occur in some trophoblast cells, but the exact pattern of expression is not certain. Low et al. (1990) did not detect MHC class I protein in trophoblasts within the placentomes, but reported variable expression in the interplacentomal chorionic membrane. However, Davies et al. (2000) reported expression of class I protein in trophoblasts within the placentome, but only in the arcade region. Ellis et al. (1998) concentrated on the control of MHC class I expression in the main region of fetomaternal exchange, the placentomal villi. In agreement with the other two studies, class I protein was not detected in the uninucleate cells that constitute most of the trophoblast cells in this region. However, small amounts of class I mRNA were detected, indicating that downregulation occurs at both transcriptional and post-transcriptional stages. This study also generated tentative evidence of MHC class I protein expression in some binucleate trophoblast cells throughout the placentome, and was supported by the detection of high concentrations of class I mRNA in these cells.

Expression of MHC class I in binucleate cells could have implications for the immunological status of the fetus. Binucleate cells, which are present in cattle, sheep, goats and deer (Wooding, 1992), are derived from uninucleate trophoblast cells by nuclear division without cytokinesis, and so it is possible that inhibition of class I expression is removed during this differentiation process. Also, binucleate cells have an unusual fate: they are extruded through to the maternal side of the placenta where they fuse with maternal endometrial cells to form extensive hybrid syncytia (in sheep and goats) or smaller hybrid trinucleate minisyncytia (in cattle and deer). Although these fetomaternal fusion units are known to secrete hormones involved in the maintenance of pregnancy and development of the mammary gland (Wooding and Beckers 1987), their hybrid nature could make their immunological function even more important. These antigenically mixed cells could represent an important route by which the ruminant fetus ensures its own survival.

Thus, the aims of this study were to isolate bovine binucleate cells to confirm that they do express MHC antigens, and to determine the nature of the genes and molecules involved.

\section{Materials and Methods}

\section{Purification of bovine binucleate trophoblast cells and peripheral blood mononuclear cells (PBMCs)}

All material was collected from an inbred herd of cattle carrying well characterized MHC haplotypes (Ellis et al., 1996).
Binucleate trophoblast cells were prepared from three near term placentae (day 275 of gestation; normal duration of gestation is 279-290 days) using a modification of the procedure described by Wango et al. (1990) for purification of sheep and goat binucleate cells. In brief, the fetal and maternal components of the placentome were teased apart and fetal villi were minced into sterile PBS. Villi were washed three times in saline before enzymatic disaggregation in $1 \mathrm{~g}$ protease $\mathrm{I}^{-1}$ (Bacillus polymyxa type IX protease, Dispase; Roche, Lewes) in PBS for $2 \mathrm{~h}$ at $37^{\circ} \mathrm{C}$. Protease activity was quenched by the addition of $10 \%(\mathrm{v} / \mathrm{v})$ fetal calf serum (Life Technologies, Paisley), and the cell suspension was filtered through $100 \mu \mathrm{m}$ gauze before two washes in PBS. The cells were then resuspended in PBS and layered over two different densities (1.046 $\mathrm{g}^{-1}$ and $\left.1.060 \mathrm{~g} \mathrm{l}^{-1}\right)$ of a mixture of PBS $\left(1.012 \mathrm{~g} \mathrm{I}^{-1}\right)$ and polysucrose $\left(1.083 \mathrm{~g} \mathrm{I}^{-1}\right.$, Histopaque 1083; Sigma, Poole). After centrifugation for $30 \mathrm{~min}$ at $1600 \mathrm{~g}$, cells aspirated from the lower interface were $80-90 \%$ pure binucleate cells, as revealed by the two characteristic large nuclei, which were clearly visible by phase contrast microscopy. None of the cells in the isolate adhered to tissue culture plastic within $24 \mathrm{~h}$, and so these cells were identified as non-adherent trophoblast cells, rather than fibroblast, endothelial or endometrial cells.

Heparinized blood was collected from cows by jugular venepuncture at the time of placentome collection, and fetal blood was withdrawn from the umbilical vein. Blood was diluted in an equal volume of PBS and layered over $1.083 \mathrm{~g}$ polysucrose $\mathrm{I}^{-1}$ before centrifugation at $1600 \mathrm{~g}$ for $20 \mathrm{~min}$. PBMCs were aspirated from the interface, and further removal of erythrocytes from fetal PBMCs was carried out by rapid hypotonic lysis. The PBMCs were washed twice in PBS.

\section{Immunodetection of binucleate cell MHC class I protein antigens}

Cytospin preparations of purified binucleate cells were prepared and used for immunocytochemistry. Cytospins were fixed in acetone at $4^{\circ} \mathrm{C}$ for $2 \mathrm{~min}$, rehydrated and blocked in PBS with $10 \%(\mathrm{v} / \mathrm{v})$ goat serum for $20 \mathrm{~min}$. The slides were then incubated for $60 \mathrm{~min}$ with mouse IgG, the monoclonal antibody ILA88 or the monoclonal antibody ILA19, at a concentration of $10 \mathrm{mg} \mathrm{l}^{-1}$ in PBS with $10 \%$ goat serum. ILA88 recognizes a monomorphic conformationally independent determinant on bovine MHC class I heavy chain molecules (Toye et al., 1990) and ILA19 recognizes a monomorphic determinant on bovine MHC class I molecules, which is conformationally dependent, requiring the class I heavy chain to be bound to the $\beta_{2-}$ microglobulin light chain (Bensaid et al., 1989). After three washes in PBS, the slides were incubated in PBS containing $10 \%$ bovine serum and $10 \mathrm{mg}$ caprine anti-mouse Ig antibody $\mathrm{I}^{-1}$ conjugated to fluorescein isothiocyanate (goat anti-mouse-FITC; Dako, Ely) in the dark for 30 min. After three washes in PBS, the cytospins were counterstained with the nuclear stain 4,6-diamidino-2-phenylindole (DAPl; Sigma) and visualized by fluorescence microscopy. 


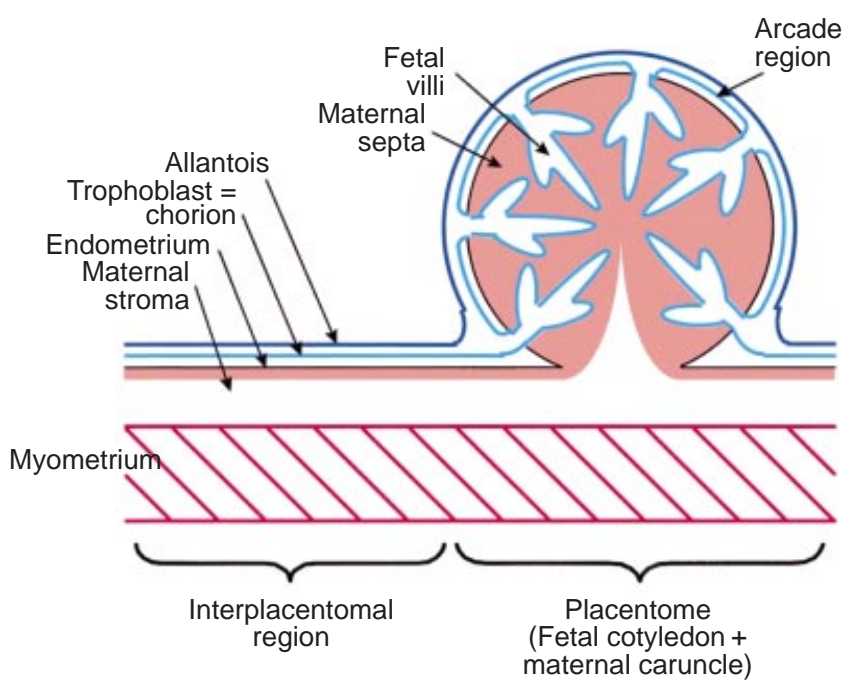

Fig. 1. Schematic diagram of the relationship between fetal (blue) and maternal (pink) tissues in the bovine placenta. In the interplacentomal areas, the chorioallantois overlies the endometrium. In the placentome, where most fetomaternal exchange is thought to take place, the trophoblast develops villi, which invade the pre-existing specialized endometrial and stromal structure, the caruncle.

Binucleate cells and fetal PBMCs were used for detection of immunoprecipitated radiolabelled MHC class I molecules by SDS-PAGE. Five million of each type of cell were incubated in $2 \mathrm{ml}$ aliquots of Roswell Park Memorial Institute (RPMI) 1640 medium in the absence of methionine (Life Technologies) with $10 \%$ fetal calf serum for 30 min at $37^{\circ} \mathrm{C}$ in $5 \% \mathrm{CO}_{2}$ in air, after which $3.7 \mathrm{MBq}^{35} \mathrm{~S}$-labelled methionine was added to each culture tube for a further $18 \mathrm{~h}$. Each aliquot of cells was washed in $20 \mathrm{ml}$ iced PBS with $1 \mathrm{mmol}$ polymethylsulphonylfluoride (Sigma) $\mathrm{I}^{-1}$ and resuspended in iced lysis buffer containing $0.5 \%(\mathrm{v} / \mathrm{v})$ nonidet P40 detergent (Sigma) in 20 mmol Tris buffer $\mathrm{I}^{-1} \mathrm{pH}$ 7.6 with $10 \mathrm{mmol}^{\text {EDTA }} \mathrm{I}^{-1}, 10 \mathrm{mmol} \mathrm{NaCl} \mathrm{l}^{-1}$ and $1 \mathrm{mmol}$ polymethylsulphonylfluoride $\mathrm{I}^{-1}$. After a $30 \mathrm{~min}$ incubation, the mixture was centrifuged at $1500 \mathrm{~g}$ for $15 \mathrm{~min}$ at $4^{\circ} \mathrm{C}$, and the lysate supernatant was aspirated and retained in three aliquots for each type of cell. Each aliquot of lysate was pre-cleared by overnight incubation at $4^{\circ} \mathrm{C}$, with $250 \mu \mathrm{l}$ fixed Staphylococcus aureus cells (Pansorbin; Pharmacia, Amersham), followed by incubation alone, or with $4 \mu \mathrm{g}$ of either the ILA88 or ILA19 antibodies. The MHC class I molecule-antibody complexes were then immunoprecipitated with $50 \mu \mathrm{l}$ Staphylococcus cells. Each pellet was divided into two sub-aliquots, one of which was deglycosylated with $25 \mathrm{U}$ glycosidase- $\mathrm{F}$ (Roche) $\mathrm{ml}^{-1}$ for $30 \mathrm{~min}$, and then both sub-aliquots were denatured and reduced by boiling in SDS-PAGE loading buffer before electrophoresis on a $15 \%(\mathrm{w} / \mathrm{v})$ polyacrylamide gel, which was then dried and autoradiographed.
Table 1. PCR primer pairs used to amplify portions of bovine major histocompatibility complex (MHC) class I cDNA

\begin{tabular}{ll}
\hline Primer pair $\quad$ Amplicon size \\
\hline
\end{tabular}

A: 5'-GGCTACGTGGACGACACG-3' and

B: 5'-CGCTCTGGTTGTAGTAGCC-3'

C: 5'-GGCTACTACAACCAGAGCG-3' and

D: 5'-CCCTCCACGTAGTTCCT-3'

238

The primers were designed to be complementary to conserved regions of the bovine MHC class I genes, and to amplify across variable regions to distinguish between alleles. Primers $\mathrm{A}$ and $\mathrm{B}$ are complementary to regions within exon 2, and primers $C$ and $D$ are complementary to regions within exons 2 and 3, respectively. Exons 2 and 3 encode the $\alpha_{1}$ and $\alpha_{2}$ domains of the mature MHC class I molecule, which form the peptide binding groove. This region is by far the most variable region of the molecule. Individual cattle are thought to carry between two and six different MHC class I alleles (Ellis et al., 1999).

\section{Characterization of binucleate cell MHC class I mRNA expression}

mRNA was prepared from aliquots of $5 \times 10^{6}$ binucleate cells, fetal PBMCs and maternal PBMCs by cell lysis and extraction on oligo-dT coated beads (Dynabeads mRNA Direct Kit; Dynal, Bromborough), and cDNA was generated by reverse transcription (cDNA Synthesis System; Life Technologies). Fragments of MHC class I cDNA were then amplified from these samples using two primer pairs designed to be complementary to non-variable regions of the class I gene (Table 1). Thirty-five PCR cycles $\left(94^{\circ} \mathrm{C}\right.$ for $1 \mathrm{~min}, 55^{\circ} \mathrm{C}$ for $2 \mathrm{~min}, 72^{\circ} \mathrm{C}$ for $2 \mathrm{~min}$ ) were carried out. The PCR volume was $100 \mu \mathrm{l}$ and contained $200 \mathrm{mmol}$ Tris- $\mathrm{HCl}$ $\mathrm{I}^{-1}(\mathrm{pH} 8.4), 50 \mathrm{mmol} \mathrm{KCl} \mathrm{l^{-1 }}, 5 \mathrm{mmol} \mathrm{MgCl}_{2} \mathrm{I}^{-1}, 25 \mu \mathrm{mol}$ dATP, dCTP, dGTP and dTTP I-1, $1 \mu \mathrm{mol} \mathrm{I}^{-1}$ of each primer, $2.5 \cup$ Taq polymerase (Gibco BRL) and $10 \%$ of the cDNA produced from each cell sample. PCR products were separated by $1.5 \%(\mathrm{w} / \mathrm{v})$ agarose gel electrophoresis, phenolextracted and ligated into a Smal-digested M13mp18 vector (Pharmacia), and then used to transform TG1 strain Escherichia coli. At least 12 clones from each sample were sequenced by the dideoxy chain termination method (Sequenase; USB, Cleveland).

\section{Results}

\section{Immunodetection of binucleate cell MHC class I protein} antigens

A subset of binucleate cells showed staining with the antibodies ILA88 and ILA19, which recognize bovine MHC class I molecules (Fig. 2), and this staining was variable in intensity. Similar results were obtained with material from three different pregnancies.

Immunoprecipitation of MHC class I molecules expressed in cells from three pregnancies yielded similar results, and an autoradiograph of an SDS-PAGE gel of 

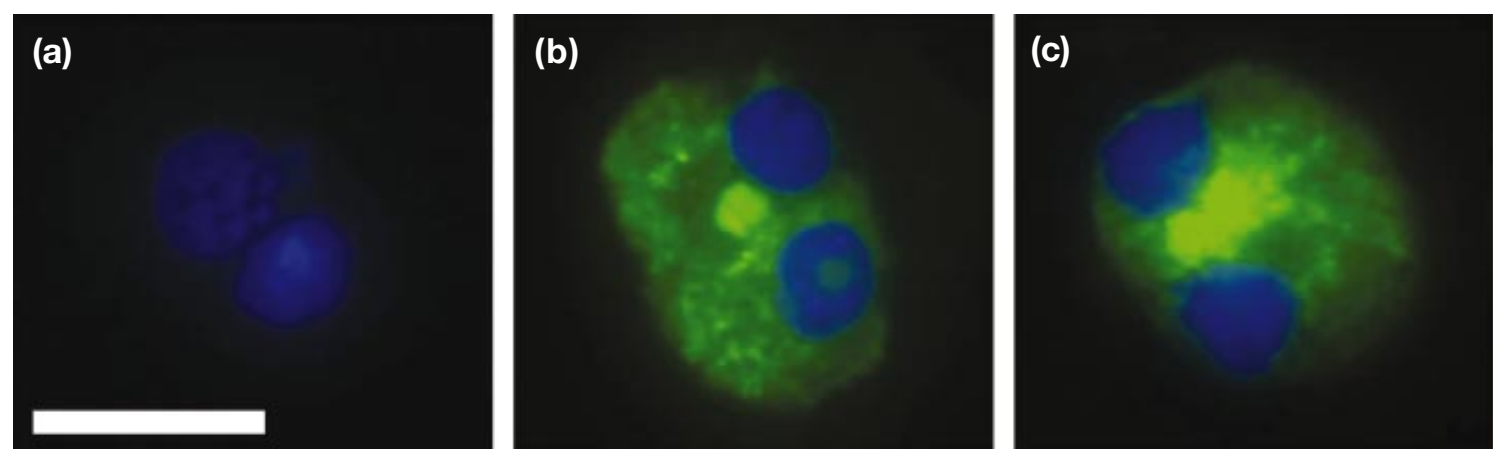

Fig. 2. Immunocytochemical detection of major histocompatibility complex (MHC) class I antigens in cytospin preparations of bovine binucleate trophoblast cells. Cells were incubated with (a) mouse IgG, (b) mouse ILA-88 anticlass I antibody or (c) mouse ILA-19 anti-class I antibody followed by fluorescein isothiocyanate (FITC)-conjugated anti-mouse Ig antibody (green) and 4,6-diamidino-2-phenylindole (DAPI) nuclear stain (blue). Scale bar represents $20 \mu \mathrm{m}$.

proteins derived from a single pregnancy is reproduced (Fig. 3). The antibodies ILA88 and ILA19 precipitated a major protein species of approximately $45 \mathrm{kDa}$, which was reduced in size by deglycosylation and this corresponds to the expected properties of the class I heavy chain. Although differing in band intensity, the proteins precipitated from PBMCs and binucleate cell lysates were otherwise similar. In mature MHC class I molecules, the heavy chain associates with a light chain, $\beta_{2}$-microglobulin, but this is not detected by incorporation of radiolabelled methionine, as it does not contain any methionine residues.

\section{Characterization of binucleate cell MHC class I mRNA expression}

Binucleate cells, and fetal and maternal PBMCs from all three pregnancies yielded PCR products with both primer pairs. An agarose gel showing the products derived from one pregnancy is presented (Fig. 4). The primers were designed to amplify all class I genes, so that the PCR products were cloned and at least 12 clones were sequenced in each case. The class I mRNA identified in each tissue is presented (Table 2). All of the PCR products had sequences that were identical to published bovine MHC class I sequences, probably because many of the published sequences are derived from animals in the herd that was used in the present study. It is not known how many MHC loci are expressed in cattle, although the number of loci probably varies between haplotypes (Ellis et al., 1999). Most of the sequences derived from the binucleate cells were identical to sequences from the corresponding fetal PBMCs (15 of 21, 13 of 16 and 11 of 12 in the three pregnancies), but the remainder ( 6 of 21,3 of 16,1 of 12) had an identical sequence to HD15, a previously published bovine class I sequence (Ellis et al., 1996, 1999). HD15 is a non-polymorphic putative non-classical class I gene that is transcribed in lymphocytes at a low rate, although to date there is no evidence of HD15 expression (a confirmed 'non-classical' class I product has not yet been
Table 2. Major histocompatibility complex (MHC) class I cDNAs detected in fetal peripheral blood mononuclear cells (PBMCs), placental binucleate cells and maternal PBMCs in three pregnancies

\begin{tabular}{llll}
\hline & Fetal PBMCs & $\begin{array}{c}\text { Binucleate } \\
\text { trophoblast } \\
\text { cells }\end{array}$ & $\begin{array}{c}\text { Maternal } \\
\text { PBMCs }\end{array}$ \\
\hline Pregnancy 1 & HD6 & HD6 & HD6 \\
& HD6.2 & HD6.2 & HD1 \\
Pregnancy 2 & HD15 & HD7 \\
& D18.3 & D18.2 & D18.2 \\
& HD6 & HD18.3 & D18.3 \\
Pregnancy 3 & HD6 & HD6 & HD7 \\
& MAN8 & MAN8 & D18.1 \\
& & HD15 & HD6 \\
\hline
\end{tabular}

The sequences of all the PCR products were identical to published bovine MHC class I sequences, previously derived from animals in the herd used in the present study (Ellis et al., 1999).

described in cattle). The binucleate cells yielded some sequences that were also present in corresponding maternal and fetal PBMCs, and some sequences that were present in the fetal PBMCs but absent in maternal PBMCs. These sequences presumably represent paternally inherited MHC class I alleles. However, the binucleate cells did not yield sequences present in maternal PBMCs but not present in fetal PBMCs, indicating that the binucleate cell samples were not significantly contaminated by maternal cells.

\section{Discussion}

The results from the present study confirm the tentative suggestion (Ellis et al., 1998) based on immunohistology and in situ hybridization that, in contrast to most bovine 


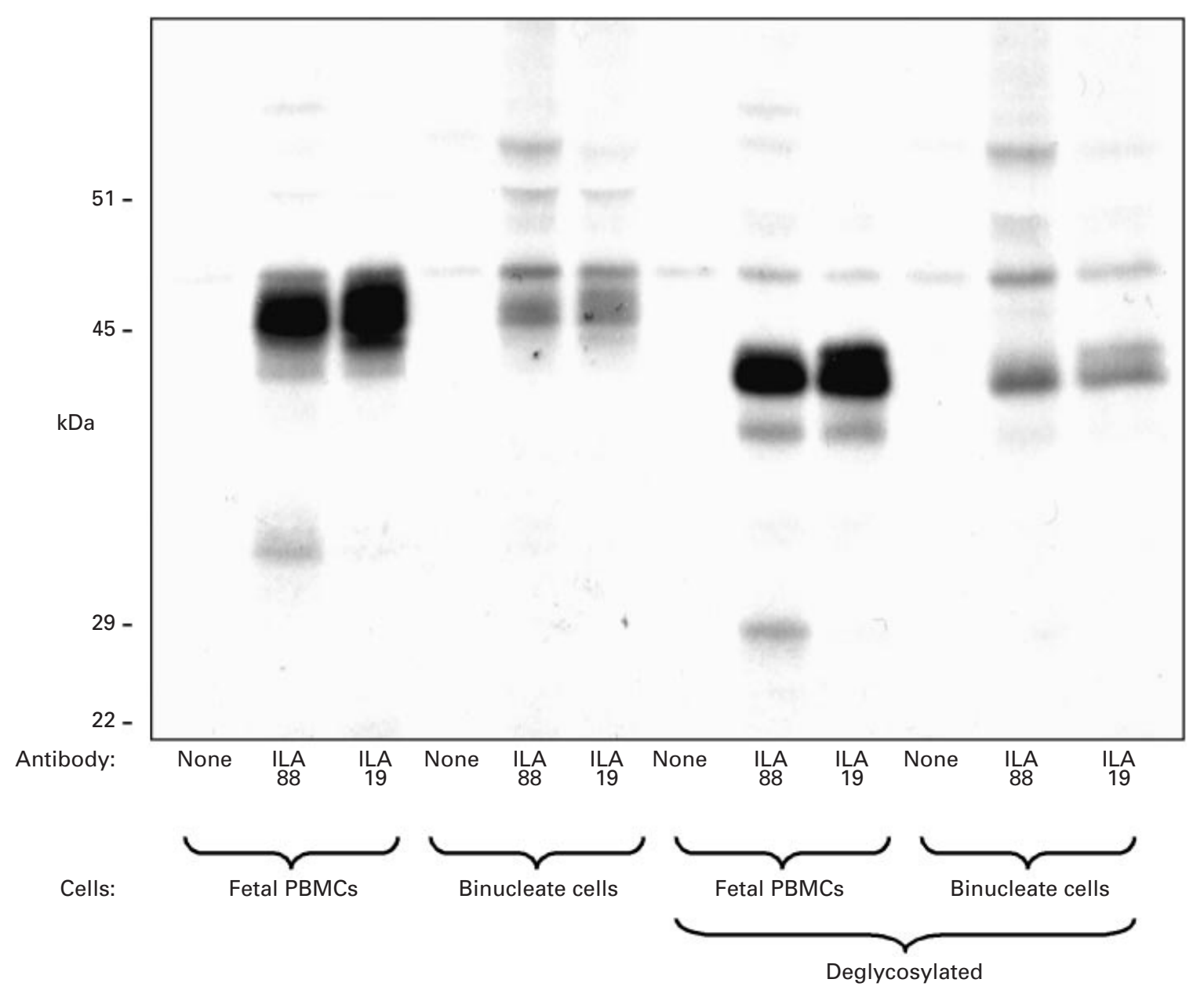

Fig. 3. Autoradiograph of a SDS-PAGE gel of immunoprecipitated radiolabelled proteins derived from calf peripheral blood mononuclear cells (PBMCs) and binucleate trophoblast cells. The antibodies ILA88 and ILA99 recognize bovine major histocompatibility complex (MHC) class I molecules. All samples were run in glycosylated form and after deglycosylation with glycosidase F.

trophoblast cells, some binucleate cells express MHC class I molecules. Evidence of anti-MHC class I antibody staining of apparently binucleated cells in tissue sections has now been corroborated by staining of individual dispersed binucleate cells. Furthermore, this staining has been shown by immunoprecipitation studies to represent antibody binding to a molecule of identical size to MHC class I.

Thus, despite the relatively non-invasive placentation of cattle, pregnant cows may be exposed to 'foreign' polymorphic paternally derived MHC. The immunological role of MHC may be complex because the binucleate trophoblasts expressing MHC class I fuse with maternal cells. The resulting fetomaternal trinucleate cell minisyncytia are known to play an important role in the hormonal support of pregnancy and mammary development (Wooding and Beckers 1987), but these results indicate that the trinucleate cell minisyncytia may also provide some form of immunological support to pregnancy. Indeed, these studies in cattle may be seen as taking our understanding of the immunology of pregnancy to a stage beyond the 'fetusas-graft' concept: not only does the bovine fetal semiallograft survive in the presence of the maternal immune system, but it also continuously presents the immune system with hybrid cells that may express a mixture of maternal and fetal antigens. In addition, as the main function of MHC class I antigen is to present potentially foreign peptides to lymphocytes, it is of interest to note that hybrid trinucleate cells may express maternal peptide bound to maternally derived class I molecules, maternal peptide bound to fetal MHC class I, fetal peptide bound to maternal MHC class I molecules and fetal peptide bound to fetal MHC class I molecules.

The transcription of sequences identical to that of the evolutionarily divergent gene HD15 (Ellis et al., 1999) in trophoblast cells is of uncertain significance. It is possible that preferential expression of HD15 indicates a dedicated function for this gene in the immunology of pregnancy, perhaps similar to that of non-classical HLA-G in human 


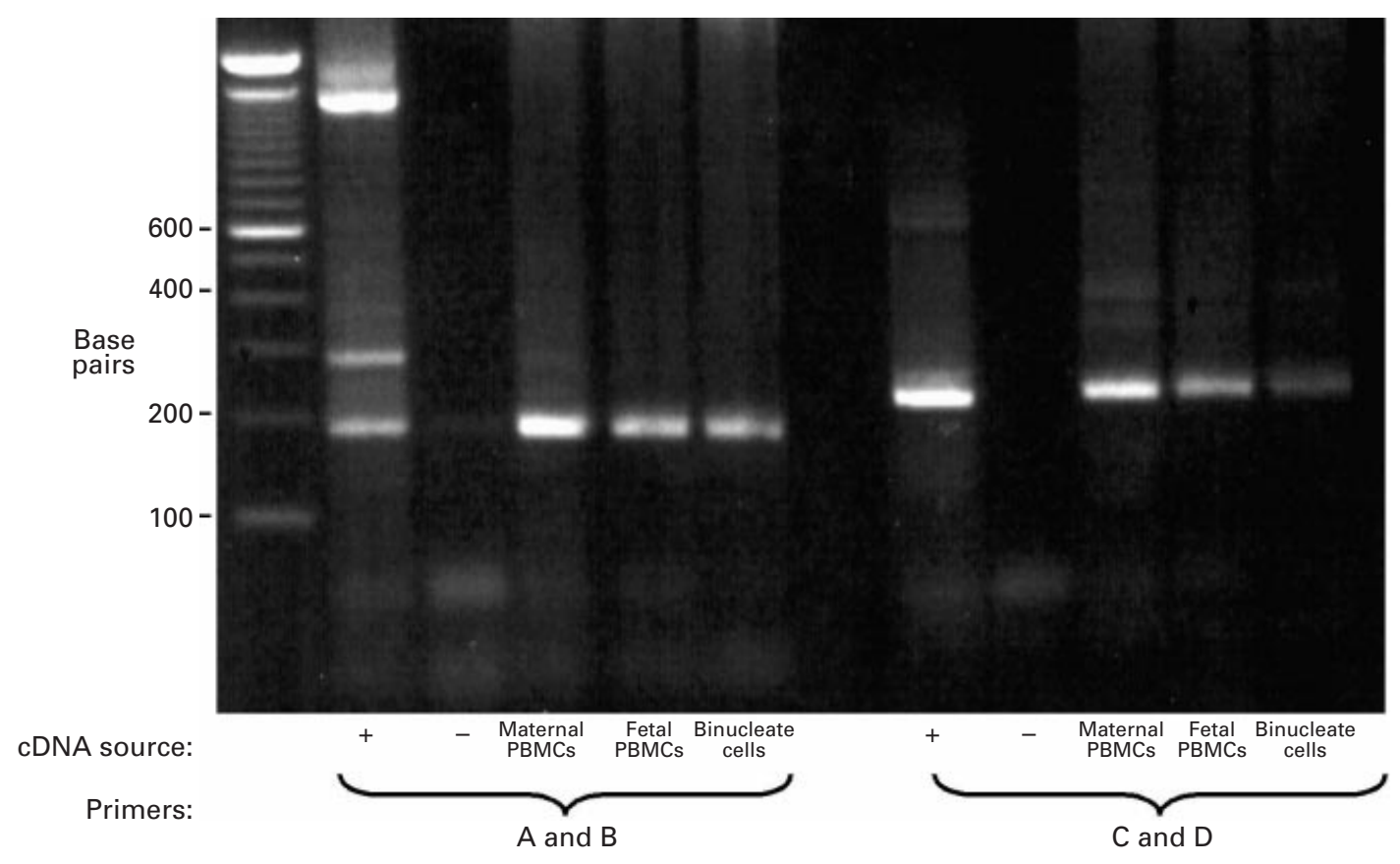

Fig. 4. Agarose gel electrophoresis of products of PCR amplification of cDNA derived from maternal peripheral blood mononuclear cells (PBMCs), fetal PBMCs and binucleate cells with primers complementary to regions of the bovine major histocompatibility complex (MHC) class I heavy chain gene. Positive (+) and negative (-) symbols denote positive and negative PCR controls, respectively.

trophoblast. However, it is not known whether HD15 mRNA is translated or whether any HD15 protein is translocated to the cell surface.

It is not clear why only a subset of isolated binucleate cells express MHC class I antigens. This may be an artefact of the isolation of cells at different stages of differentiation and development: if binucleate cells upregulate expression of MHC class I antigens part way through the period between nuclear division and fusion with maternal cells, then only a subset of the binucleate cells isolated at any one time would be expected to show evidence of MHC class I expression. A second possibility is that only a subset of binucleate cells ever upregulate $\mathrm{MHC}$ class I. The reason for the presence of $\mathrm{MHC}^{+}$and $\mathrm{MHC}^{-}$populations is unclear, but binucleate cells are heterogeneous with respect to other parameters, including hormone synthesis (Wooding et al., 1996) and cytokeratin staining (Nakano et al., 2001). A third possibility is that trophoblast cells that do not stain positively with ILA88 or ILA19 express the product of the HD15 MHC class I gene. Expression of HD15 protein has not been detected in any experimental system, and so it is not known whether ILA88 or ILA19 recognize this molecule. In addition, it is not known whether HD15 is co-expressed with classical MHC class I genes in the same trophoblast cells or whether different trophoblast cell populations express different genes.

The bovine trophoblast binucleate cell represents an intriguing route by which fetal antigens may be exposed to the maternal immune system. Although it remains to be demonstrated whether fetal MHC class I remains up- regulated after fetomaternal syncytialization, there is evidence that maternal lymphocytes are exposed to fetal alloantigens, as maternal alloantibody responses have been reported during late pregnancy in cattle (Newman and Hines, 1980). Indeed, it could be argued that binucleate cells are the only likely route by which maternal alloimmunization could occur, as the relatively noninvasive epitheliochorial placenta of cattle makes leakage of fetal blood cells and trophoblast fragments into the maternal blood (as occurs in haemochorial human and rodent placentas) unlikely.

However, in one important way, the bovine fetus is similar to human and equine fetuses, which despite downregulating $\mathrm{MHC}$ antigens in most of the placenta, apparently 're-upregulate' MHC in a trophoblast subset particularly exposed to maternal tissues. Such deliberate exposure of the mother to fetal MHC during pregnancy indicates that a degree of maternal recognition of fetal MHC may in fact be beneficial. Furthermore, in cows and horses, in which the MHC expressed is polymorphic, it could be argued that fetomaternal histoincompatibility may also improve the outcome of pregnancy. It has been proposed that various forms of pregnancy histo-incompatibility increase the size of the placenta in mice, improve the success of pregnancy in humans and encourage efficient postpartum placental dehiscence in cattle (Billington, 1964; Joosten et al., 1991; Ober, 1992). Thus, the present study raises the possibility that fetomaternal histo-incompatibility may encourage successful pregnancy in cattle. 
The authors would like to thank B. Charleston and M. Fray for their input into this work. This study was funded by the Wellcome Trust.

\section{References}

Bainbridge DRJ (2000) Evolution of mammalian pregnancy in the presence of the maternal immune system Reviews of Reproduction 5 67-74

Bensaid A, Kaushal A, Baldwin CL, Clevers H, Young JR, Kemp SJ, Machugh ND, Toye PG and Teale AJ (1989) Identification of expressed bovine class I MHC genes at two loci and demonstration of physical linkage Immunogenetics 33 247-254

Billington WD (1964) Influence of immunological dissimilarity of mother and foetus on size of placenta in mice Nature 202 317-318

Davies CJ, Fisher PJ and Schlafer DH (2000) Temporal and regional regulation of major histocompatibility complex class I expression at the bovine uterine/placental interface Placenta 21 194-202

Donaldson WL, Zhang CH, Oriol JG and Antczak DF (1990) Invasive equine trophoblast expresses conventional class I major histocompatibility complex antigens Development 110 63-71

Ellis SA, Staines K and Morrison WI (1996) CDNA sequence of cattle MHC class I genes transcribed in serologically defined haplotypes A18 and A31 Immunogenetics 43 156-161

Ellis SA, Sargent IL, Charleston B and Bainbridge DRJ (1998) Regulation of MHC class I gene expression is at transcriptional and posttranscriptional level in the bovine placenta Journal of Reproductive Immunology 37 103-115

Ellis SA, Holmes EC, Staines KA, Smith KB, Stear MJ, McKeever DJ, MacHugh ND and Morrison WI (1999) Variation in the number of expressed MHC genes in different cattle class I haplotypes Immunogenetics $50319-328$

Gogolin-Ewens KJ, Lee CS, Mercer WR and Brandon MR (1989) Sitedirected differences in the immune response to the fetus Immunology $\mathbf{6 6}$ $312-317$

Joosten I, Sanders MF and Hansen (1991) Involvement of major histocompatibility complex class I compatibility between dam and calf in the aetiology of bovine retained placenta Animal Genetics 22 455-463

Kanbour A, Ho H-N, Misra DN, MacPherson TA, Kunz HW and Gill TJ (1987) Differential expression of MHC class I antigens on the placenta of the rat Journal of Experimental Medicine 166 1861-1882

Low BG, Hansen PJ and Gogolin-Ewens KJ (1990) Expression of major histocompatibility complex antigens on the bovine placenta Journal of Reproduction and Fertility 90 235-243

Medawar P (1953) Some immunological and endocrinological problems raised by the evolution of viviparity in vertebrates Symposia of the Society for Experimental Biology 7 320-338

Nakano H, Takahashi T, Imai K and Hashizume K (2001) Expression of placental lactogen and cytokeratin in bovine placental binucleate cells in culture Cell and Tissue Research 303 263-270

Newman MJ and Hines HC (1980) Stimulation of maternal anti-lymphocyte antibodies by first gestation bovine fetuses Journal of Reproduction and Fertility 60 237-241

Ober C (1992) The maternal-fetal relationship in human pregnancy: an immunogenetic perspective Experimental and Clinical Immunogenetics 9 1-14

Ramsoondar JJ, Christopherson RJ, Guilbert LJ, Dixon WT, Chahary A, Ellis SA, Wegman TG and Piedrahita JA (1999) Lack of class I major histocompatibility antigens on trophoblast of peri-implantation blastocysts and term placenta in the pig Biology of Reproduction $60387-397$

Redman CWG, McMichael AJ, Stirrat GM, Sunderland CA and Ting A (1984) Class I MHC antigens on human extravillous trophoblast Journal of Immunology 52 457-468

Toye PG, MacHugh ND, Bensaid AM, Alberti S, Teale AJ and Morrison WI (1990) Transfection into mouse L cells of genes encoding two serologically and functionally distinct bovine class I MHC molecules Immunology 70 20-26

Wango EO, Heap RB and Wooding FBP (1990) Progesterone and 5 $\beta$ pregnanediol production by isolated fetal placental binucleate cells from sheep and goats Journal of Endocrinology 129 283-289

Wooding FBP (1992) The synepitheliochorial placenta of ruminants: binucleate cell fusions and hormone production Placenta 13 101-113

Wooding FBP and Beckers JF (1987) Trinucleate cells and the ultrastructural localisation of bovine placental lactogen Cell and Tissue Research 247 667-673

Wooding FBP, Morgan G, Monaghan S, Hamon M and Heap RB (1996) Functional specialization in the ruminant placenta: evidence for two populations of fetal binucleate cells of different selective synthetic capacity Placenta 17 75-86

Received 14 May 2001

First decision 26 June 2001.

Accepted 2 August 2001. 